\title{
Tranexamic acid for the treatment of postpartum hemorrhage: placebo controlled study
}

\author{
Rashmi Naganagoudaru ${ }^{1 *}$, Vinaya G. ${ }^{2}$
}

\begin{abstract}
${ }^{1}$ Department of Obstetrics and Gynecology, Raichur Institute of Medical sciences, Raichur, Karnataka, India
${ }^{2}$ Department of Obstetrics and Gynecology, Koppal Institute of Medical sciences, Koppal, Karnataka, India
\end{abstract}

Received: 07 May 2017

Accepted: 03 June 2017

\section{*Correspondence:}

Dr. Rashmi Naganagoudaru,

E-mail: patil.shreeharsha@gmail.com

Copyright: (c) the author(s), publisher and licensee Medip Academy. This is an open-access article distributed under the terms of the Creative Commons Attribution Non-Commercial License, which permits unrestricted non-commercial use, distribution, and reproduction in any medium, provided the original work is properly cited.

\section{ABSTRACT}

Background: Each year, worldwide about 530,000 women die from causes related to pregnancy and child birth. Obstetric hemorrhage is the leading cause of maternal mortality accounting for between one quarter and one third of deaths, most of which occur in postpartum period. The objective of the study was to study the effectiveness of tranexamic acid in reducing the blood loss in women with PPH.

Methods: Study done on 100 adult women with clinically diagnosed postpartum hemorrhage, satisfying inclusion and exclusion criteria, following vaginal delivery of baby; women may have delivered their babies at Obstetrics and Gynecology department, Karnataka Institute of Medical Sciences (KIMS), Hubli or outside, with hospital admission following delivery. 50 patients will receive standard protocol with placebo for the treatment of PPH and 50 women will receive standard protocol with tranexamic acid $(1 \mathrm{gm}$ slow IV, if after $30 \mathrm{~min}$ bleeding continues after the first dose, a second dose may be given approximate rate of $1 \mathrm{ml} / \mathrm{min}$ ).

Results: Mean blood loss in the control group was $744 \pm 102 \mathrm{ml}$, whereas in Tranexamic acid group blood loss was $626 \pm 113 \mathrm{ml}$. There was no patient requiring surgical intervention or hysterectomy in either group \& there was no maternal mortality in either group and no thrombogenic side effect seen either in mother or baby in both the groups. Conclusions: It was concluded that Tranexamic acid is effective in reducing blood loss in women clinically diagnosed with PPH.

Keywords: Blood loss, Hemorrhage, Tranexamic acid, Vaginal delivery

\section{INTRODUCTION}

Each year, worldwide about 530,000 women die from causes related to pregnancy and childbirth. Almost all (99\%) of the deaths are in low and middle-income countries. Obstetric hemorrhage is the leading cause of maternal mortality accounting for between one quarter and one third of deaths, most of which occur in postpartum period. ${ }^{1}$ About 14 million mothers develop postpartum hemorrhage each year. And about $2 \%$ of them will die, with an average interval from onset to death of about 2-4 hours. Systemic anti-fibrinolytic agents are widely used in surgery to prevent clot breakdown (fibrinolysis) in order to reduce surgical blood loss. ${ }^{2}$ This study will provide a reliable scientific basis for recommendations as to whether or not tranexamic acid should be used in the treatment of postpartum hemorrhage.

If tranexamic acid reduces mortality and morbidity in women with postpartum hemorrhage, it could be of considerable significance as global commitment to the millennium developmental goal (MDG) of reducing maternal death by three quarters by the year 2015, a commitment that requires a reduction of the maternal mortality ratio by $5.5 \%$ each year. Because maternal 
hemorrhage accounts for over a quarter of deaths, an effective treatment for postpartum hemorrhage would contribute importantly to the MDG of reducing maternal mortality. The objective of study was to study the effectiveness of Tranexamic acid in reducing the blood loss in women with PPH.

\section{METHODS}

This is prospective, randomized placebo-controlled study carried out at Department of Obstetrics and Gynaecology, Karnataka Institute of Medical Sciences, Hubli. Study was done on 100 parturient women with clinically diagnosed postpartum hemorrhage, satisfying inclusion and exclusion criteria

The study was undertaken during May 2010 to April 2011. Permission for the study was obtained from the College authorities prior to commencement.

Women who delivered their babies at KIMS hospital or outside, with hospital admission following delivery were selected for the study. Who has been clinically diagnosed postpartum hemorrhage, satisfying inclusion and exclusion criteria, following vaginal delivery of a baby.

\section{Inclusion criteria}

Clinical diagnosis of PPH may be based on any of following:

- Estimated blood loss after vaginal delivery of baby $>500 \mathrm{ml} \mathrm{OR}$

- Estimated blood loss enough to compromise the hemodynamic status of the women.

\section{Exclusion criteria}

- Severe medical and surgical complications involving the heart, liver, kidney, brain disease and blood disorders

- Allergy to tranexamic acid

- History of thrombo-embolic disorders.

Data Collection Method: All women following vaginal delivery of their babies at KIMS hospital or outside, with hospital admission following delivery. Clinically diagnosed PPH, satisfying inclusion and exclusion criteria were considered.

- Detailed history was taken and general physical and obstetrics examination was done.

- Written and informed consent for participating in the trial

Patients were allocated into two groups:

- Group 1: control group 50 cases

- Group 2: study group 50 cases.

\section{Control group}

standard protocol for the treatment of PPH along with placebo (normal saline, $10 \mathrm{ml}$ ) was given following diagnosis of PPH.

\section{Study group}

tranexamic acid $1 \mathrm{gm}$ IV (if after $30 \mathrm{~min}$ bleeding continues, $1 \mathrm{gm}$ can be repeated) along with standard protocol for treatment of $\mathrm{PPH}$ was given following diagnosis of PPH.

\section{Evaluation}

Estimation of blood loss: After delivery of the baby amniotic fluid was allowed to drain away (if present) and BRASS-V drape was used to collect blood and also to quantify amount of blood collected. The drape has a calibrated and funneled collecting pouch, incorporated within a plastic sheet that is placed under the buttocks of the patient immediately after the delivery of baby.

The upper end of the sheet has a belt, which is loosely tied around the women's abdomen to optimize blood collection. Blood clots were weighed separately. Blood soaked swabs were weighed, the known dry weight subtracted and the calculated volume added to that of drape $(1 \mathrm{gm}=1 \mathrm{ml})$

- Placenta and membranes were examined for completeness after expulsion.

- Vital signs: heart rate, respiratory rate and blood pressure were checked before and after delivery.

- Neonatal details were noted.

- Maternal side effects caused by tranexamic acid like visual disturbance, chest pain, calf pain, incordination was noted.

- Any surgical intervention or hysterectomy required for failed medical management was noted.

- Any maternal mortality and cause for it was evaluated.

\section{Methodology of analysis}

Once enrolled all the subjects were followed up regularly and their obstetric outcome was carefully recorded using standard proforma as mentioned in the next section.

The data and results so obtained were tabulated and analyzed using Microsoft excels spread sheet software of MS office 2007.

The student t-test was used to compare differences between the two groups. The p-value was used for testing the statistical significance of the results obtained wherever applicable. 


\section{RESULTS}

The study was conducted on hundred patients diagnosed with postpartum haemorrhage who were admitted in the department of Obstetrics and Gynecology, KIMS Hospital, Hubli. Two groups under consideration are comparable with regard to age 24.04 yrs while in tranexamic acid group was 25.36 years (Table 1 ).

Table 1: Age distribution.

\begin{tabular}{|lll|}
\hline Age (years) & Group A-control & $\begin{array}{l}\text { Group B- } \\
\text { tranexamic acid }\end{array}$ \\
\hline $19-25$ & 34 & 31 \\
\hline $26-30$ & 14 & 16 \\
\hline $31-35$ & 2 & 2 \\
\hline Total & 0 & 1 \\
\hline
\end{tabular}

Both the groups are comparable with regards to parity distribution $p$-value is not significant i.e. there is no significant difference between the number of multiparas and the primiparas in two groups. For parity distribution chi, square test is applied $\left(\chi^{2}-2.93\right)$ (Table 2).

Table 2: Parity wise distribution.

\begin{tabular}{|lll|}
\hline Parity & Group A-control & $\begin{array}{l}\text { Group B-tranexamic } \\
\text { acid }\end{array}$ \\
\hline P1 & 17 & 11 \\
\hline P2 & 16 & 16 \\
\hline P3 & 13 & 20 \\
\hline P4 & 2 & 1 \\
\hline P5 & 1 & 1 \\
\hline P6 & 1 & 1 \\
\hline
\end{tabular}

Two groups are comparable with respect to type of delivery. $P$ value is not significant $(p>0.05)$. i.e. there is no significant difference between the numbers of FTND, Assisted breech delivery, VBAC in both the groups. For the type of delivery distribution chi square test is applied $\left(\chi^{2}-1.099\right)$ (Table 3).

Table 3: Type of delivery.

\begin{tabular}{|lll|}
\hline Type of delivery & $\begin{array}{l}\text { Group A- } \\
\text { control }\end{array}$ & $\begin{array}{l}\text { Group B- } \\
\text { tranexamic acid }\end{array}$ \\
\hline FTND & 34 & 38 \\
\hline $\begin{array}{l}\text { Assisted breech } \\
\text { delivery }\end{array}$ & 9 & 8 \\
\hline VBAC & 7 & 4 \\
\hline
\end{tabular}

Two groups are comparable with regards to cause of PPH. $\mathrm{P}$ value is not significant $(\mathrm{p}>0.05)$ i.e. there is no significant between the numbers of causes like atony, tears and trauma, atony and tears, retained placenta as cause of PPH in two groups. For cause of pph distribution, chi square test is applied $\left(\chi^{2}-0.4630\right)$ (Table 4).
Table 4: Cause of PPH.

\begin{tabular}{|lll|}
\hline Cause of PPH & $\begin{array}{l}\text { Group A- } \\
\text { control }\end{array}$ & $\begin{array}{l}\text { Group B- } \\
\text { tranexamic acid }\end{array}$ \\
\hline Atony & 39 & 38 \\
\hline Tears and trauma & 7 & 9 \\
\hline Atony+ tears & 3 & 2 \\
\hline Retained placenta & 1 & 1 \\
\hline
\end{tabular}

Mean blood loss in control group was $744 \pm 102 \mathrm{ml}$ while that in tranexamic acid group was $626 \pm 113 \mathrm{ml}$ this difference between the two groups was highly significant ( $p$ value<0.0001). Hence, we can say that in terms of blood loss tranexamic acid group is more efficacious when compared to control group. For blood loss in both groups student test ( $\mathrm{t}-5.44)$ is employed (Table 5).

Table 5: Blood loss.

\begin{tabular}{|lll|}
\hline $\begin{array}{l}\text { Blood loss } \\
(\mathrm{m})\end{array}$ & $\begin{array}{l}\text { Group A- } \\
\text { control }\end{array}$ & $\begin{array}{l}\text { Group B- } \\
\text { tranexamic acid }\end{array}$ \\
\hline $500-600$ & 1 & 14 \\
\hline $600-700$ & 9 & 23 \\
\hline $700-800$ & 26 & 9 \\
\hline $800-900$ & 11 & 1 \\
\hline $900-1000$ & 0 & 1 \\
\hline$>1000$ & 3 & 2 \\
\hline
\end{tabular}

\section{DISCUSSION}

Tranexamic acid exerts its antifibrinolytic effect by blocking the lysine binding locus of the plasminogen and plasmin molecules, thereby preventing the binding of plasminogen and plasmin to the fibnin substrate. Tranexamic acid also inhibits conversion of plasminogen to plasmin by the plasminogen activators. It has been used in the treatment of bleeding for many years.

During placental delivery, fibrinogen and fibrin are rapidly degraded, whereas plasminogen activators and fibrin degradation products (FDP) increase due to activation of the fibrinolytic system. This activation can last up to 6-10 hours postpartum, causing more bleeding. It was because of this activation of the fibrinolytic system that we decided to use tranexamic acid in this trial. The present study compares the standard protocol with placebo and standard protocol with tranexamic acid in the treatment of postpartum haemorrhage.

In the present study, the mean blood loss in the two groups was $744 \pm 102 \mathrm{ml}$ in control group and $626 \pm 113 \mathrm{ml}$ in study group. This difference between the two groups is highly statistically (p-value, 0.0001) significant. Thus, tranexamic acid is highly effective in reducing blood loss.

Similar study carried out by Ming-ying Gai, in china showed that tranexamic acid significantly reduces bleeding from the time of placental delivery to $2 \mathrm{hrs}$ postpartum in LSCS. $^{3}$ P-value $<0.002$. These results 
correlated well with present study. Similar study, carried out by Yang $\mathrm{H}$ in china showed similar results. ${ }^{4}$
Tranexamic acid significantly reduced blood loss after vaginal delivery. P-value $<0.01$.

Table 6: Comparison of results of present study with other studies (control group).

\begin{tabular}{|c|c|c|c|c|c|}
\hline $\begin{array}{l}\text { Parameters } \\
\text { measured }(\mathrm{ml})\end{array}$ & Yang $\mathbf{H}$ et $\mathbf{a l}^{4}$ & Ming-ying $\mathrm{Gai}^{3}$ et al & Gohel M et ${ }^{5}$ al & Anne-sophie D et al ${ }^{8}$ & Present Study \\
\hline Blood loss & 314.8 & $439.36 \pm 191.48$ & $472.79 \pm 43.54$ & - & $744 \pm 102$ \\
\hline Thrombosis & Nil & Nil & Nil & - & Nil \\
\hline
\end{tabular}

Table 7: Comparison of results of present study with other studies (tranexamic acid group).

\begin{tabular}{|c|c|c|c|c|c|}
\hline $\begin{array}{l}\text { Parameters } \\
\text { measured (ml) }\end{array}$ & Yang $\mathrm{H}$ et al ${ }^{4}$ & Ming-ying Gai et al ${ }^{3}$ & Gohel $M$ et al ${ }^{5}$ & $\begin{array}{l}\text { Anne-sophie D et } \\
\mathrm{al}^{7}\end{array}$ & Present study \\
\hline Blood loss & 243.3 & $359.29 \pm 152.02$ & $374.92 \pm 51.46$ & - & $626 \pm 113$ \\
\hline Thrombosis & Nil & Nil & Nil & - & Nil \\
\hline
\end{tabular}

These results correlated well with study. Similar study done by Mayur $\mathrm{G}$ et al, showed similar results. ${ }^{5}$ Tranexamic acid reduces blood loss significantly from the time of placental delivery to $2 \mathrm{hrs}$ postpartum in LSCS. P-value <0.003. these results correlated well with the study.

The incidence of thrombosis during pregnancy and puerperium is 5-6 times higher than that in the general population. When the anti-fibrinolytic drug tranexamic acid is administered, the increased risk of thrombosis should be considered, in this present study no patient developed signs of thrombosis.

Suanberg and co-workers reported 67 cases treated by tranexamic acid because of abruption placenta, thrombosis occurred in none of these cases. ${ }^{6}$ Bekassy Z, included 3014 women, including 45 pregnant women given tranexamic acid to prevent bleeding at conisation of the cervix; thrombo-embolic episodes were absent. ${ }^{7,8}$

Yang H, Chinese study of 400 pregnant women with normal deliveries who received tranexamic acid during labour; no thrombosis occurred. ${ }^{4}$

Gai $\mathrm{M}$ et al, in their study of tranexamic acid in lower segment caesarean section showed no thrombosis in study group. ${ }^{3}$ Mayur $\mathrm{G}$ et al, showed no thrombosis in study group. ${ }^{5}$ In the present study no thrombosis occurred in baby, similar results were found in study done by Gai MY et al. ${ }^{3}$

\section{CONCLUSION}

This study reveals that tranexamic Acid significantly reduced the amount of blood loss in patients with postpartum haemorrhage.

\section{ACKNOWLEDGMENTS}

Authors would like to thank all the participants for their co-operation during the study.

\section{Funding: No funding sources \\ Conflict of interest: None declared}

Ethical approval: The study was approved by the Institutional Ethics Committee

\section{REFERENCES}

1. Donald Ian. Postpartum hemorrhage. In: Donald Ian, ed. Practical obstetric problems.5th ed. New Delhi:B. I. Publications Pvt Ltd;1998:748-94.

2. Christopher B, ed. A textbook of postpartum hemorrhage: a comprehensive guide to evaluation, management and surgical intervention. Jaypee Brothers Publishers;2006.

3. Gai MY, Wu LF, Su QF, Tatsumoto K. Clinical observation of blood loss reduced by tranexamic acid during and after caesarian section: a multi-center, randomized trial. European J Obstet Gynecol Reprod Biology. 2004;112(2):154-7.

4. Yang H, Zheng S, Shi C. Clinical study on the efficacy of tranexamic acid in reducing postpartum blood loss: Chin J Obstet Gynecol. 2001;36(10):5902.

5. Mayur G, Purvi P, Ashoo G, Pankaj D. Efficacy of tranexamic acid in decreasing blood loss during and after cesarean section: a randomized case controlled prospective study. $\mathrm{J}$ Obstet Gynecol India. 2007;57(3):227-30.

6. Svanberg L, Astedt B, Nilsson IM. Abruptio placentae- treatment with the fibrnolytic inhibitors Tranexamic acid. Acta Obstet Gynecol Scand. 1980;59(2):127-30. 
7. Bekassey Z, Astedt. Treatment with antifibrinolytic Tranexamic acid; risk for thrombosis? Acta Obstet Gynecol Scand. 1990;69:353-4.

8. Ducloy-Bouthors AS, Jude B, Duhamel A, Broisin F, Huissoud C, Keita-Meyer $\mathrm{H}$, et al. High-dose tranexamic acid reduces blood loss in postpartumhaemorrhage. Critical Care. 2011;15(2):R117.

Cite this article as: Naganagoudaru R, Vinaya G. Tranexamic acid for the treatment of postpartum hemorrhage: placebo controlled study. Int J Reprod Contracept Obstet Gynecol 2017;6:3071-5. 